\title{
Recipient vessel selection for head and neck reconstruction: A 30-year experience in a single institution
}

Jae-Ho Chung ${ }^{1}$, Ki-Jae Kim ${ }^{1}$, Kwang-Yoon Jung', Seung-Kuk Baek ${ }^{2}$, Seung-Ha Park ${ }^{1}$, Eul-Sik Yoon ${ }^{1}$

Departments of ${ }^{1}$ Plastic and Reconstructive Surgery and ${ }^{2}$ Otorhinolaryngology-Head and Neck Surgery, Korea University Anam Hospital, Seoul, Korea

\begin{abstract}
Background: The advance in microsurgical technique has facilitated a proper approach for reconstruction of extensive head and neck defects. For the success of free tissue reconstruction, selection of the recipient vessel is one of the most important factors. However, the vascular anatomy of this region is very complex, and a clear guideline about this subject is still lacking. In this study, we present our 30 years of experiences of free tissue reconstruction for head and neck defects. Methods: In this retrospective study, we analyzed a total of 138 flaps in 127 patients who underwent head and neck reconstruction using free tissue transfer following tumor resection between October 1986 to August 2019. Patients who underwent facial palsy reconstruction were excluded. Medical records including patient's demographics, detailed operation notes, follow-up records, and photographs were collected and analyzed.

Results: Among a total of 127 patients, 10 patients underwent a secondary operation due to cancer recurrence. The most commonly used type of flap was radial forearm flap $(n=107)$, followed by the anterolateral thigh flap $(n=18)$ and fibula flap $(n=10)$. With regard to recipient vessels, superior thyroid artery was most commonly used in arterial anastomosis (58.7\%), and internal jugular vein $(51.3 \%)$ was the first choice for venous anastomosis. The flap survival rate was $100 \%$. Four cases of venous thrombosis were resolved with thrombectomy and re-anastomosis.

Conclusion: Superior thyroid artery and internal jugular vein were reliable choices as recipient vessels. Proper recipient vessel selection could improve the result of head and neck reconstruction.
\end{abstract}

Keywords: Free tissue flap / Head and neck cancer / Microsurgery / Neck dissection

\section{INTRODUCTION}

Head and neck cancers are the sixth common cause of malignancy, with an estimated worldwide incidence of more than 600,000 new cases annually [1]. Excision of tumor in this region can cause significant defects resulting in aesthetic problems as well as functional impairment such as speech and swallowing

\section{Correspondence: Eul-Sik Yoon}

Department of Plastic and Reconstructive Surgery, Korea University Anam

Hospital, 73 Inchon-ro, Seongbuk-gu, Seoul 02841, Korea

E-mail: yesanam2@korea.ac.kr

Received July 13, 2020 / Revised September 9, 2020 / Accepted October 12, 2020 difficulty. For the reconstruction of these defects, surgery using local or pedicled flap was performed in the early days. In particular, the pectoralis major myocutaneous flap was most widely used before, however it caused severe donor site morbidity and cosmetic problems.

In recent years, microvascular reconstruction such as radial forearm flap, anterolateral thigh flap and rectus abdominis myocutaneous flap, became the mainstay of reconstructive tool for head and neck reconstruction. It could allow various modifications tailored to each defect and overcome the limitation of volume and tissue composition. 
Because these regions have an extensive and complex vascular network, choosing an appropriate recipient vessel is a very important issue that determines success of the free flap. In selection, a variety of factors can influence the accessibility and quality of recipient vessels. Patient factors such as age, smoking, diabetes mellitus, and prior radiation therapy can influence the surgeon's decision [2-5]. Sometimes, malignancy invades adjacent tissue and vessels, and may lead to a major vessel injury. These factors force surgeons to make more difficult choices. Also, a restricted selection in vessel-depleted neck of patients who underwent reoperation also make a proper reconstruction more difficult.

In general, branches of the external carotid artery such as lingual artery, facial artery, and superior thyroid artery have been considered as a proper recipient artery. In the case of recipient veins, the internal jugular vein was most commonly used [6-8]. However, there remains no consensus regarding an appropriate vessel selection, and a clear guideline about this subject is still lacking [9]. In this study, we present our 30 years of experiences of free tissue reconstruction for head and neck defects. The purpose of this study is to introduce and analyze our recipient vessel selection process in comparison with the literature review.

\section{METHODS}

A total of 138 free tissue transfers were performed for head and neck reconstruction in 127 patients between October 1986 and August 2019. Patients were included if they were diagnosed with head and neck cancer and underwent free flap reconstruction to cover the defect following tumor resection. However, patients who underwent facial palsy reconstruction were excluded. We reviewed a retrospectively collected, institutional review board-approved database (protocol number: 2020AN0019). Medical records including patient's demographics, detailed operation notes, follow-up records, and photographs were collected and analyzed.

In Korea University Anam Hospital, all surgical procedures were performed with a two-team approach. An otolaryngology surgeon was responsible for head and neck tumor resections, which were performed with neck dissection depending on nodal status. A plastic surgeon was responsible for the reconstruction of defects, including flap harvesting and vascular anastomosis. After surgery, flap monitoring was performed every hour in the intensive care unit for the first 24 hours. Then, the patient was transferred to the general ward, and the flap was monitored every 2 hours for the second and third days. In case of adverse changes such as venous congestion, flap necrosis, or lack of flap improvement despite salvage procedure, immediate exploration was performed. The patients were followed up clinically once a month during the first 6 months and every 6 months for the next few years.

\section{RESULTS}

\section{Patient demographics}

A total of 138 free tissue transfer for head and neck reconstruction in 127 patients were reviewed. Among them, nine patients had two operations and one had a total of three operations due to cancer recurrence. The patients comprised 107 males and 20 females (of these, six males and four females underwent reoperation). Among them, 45 patients (35.4\%) were smokers.

According to pathological features, the majority of cancer was squamous cell carcinoma $(\mathrm{n}=129,93.5 \%)$, followed by ameloblastoma $(n=3,2.2 \%)$ and adenoid cystic cancer $(n=3,2.2 \%)$. The tongue was the most commonly involved site $(\mathrm{n}=84$, $60.9 \%)$, followed by hypopharynx $(n=19)$ and larynx $(n=16)$. Staging based on TNM classification showed the majority of tumors to be stage IV ( $\mathrm{n}=75,54.3 \%)$. Of 138 operations, 81 (58.7\%) reconstructions were performed with type III neck dissection. Table 1 summarizes patient demographics.

\section{Flap choice and recipient vessel selection}

When classified by flap type, radial forearm free flap $(n=107$, $77.5 \%$ ) was most commonly used, followed by anterolateral thigh free flap $(\mathrm{n}=18,13.0 \%)$ and fibular free osteocutaneous flap $(n=10,7.2 \%)$ (Table 1). Table 2 summarizes our recipient vessel choice in free flap reconstruction. In our institution, superior thyroid artery and internal jugular vein were primarily used as recipient vessels. On a closer review, the superior thyroid artery was most commonly used artery $(n=81,58.7 \%)$, followed by facial artery $(\mathrm{n}=25,18.1 \%)$ and lingual artery $(\mathrm{n}=19,13.8 \%)$. Regarding the recipient vein, internal jugular vein $(n=75,51.3 \%)$ was most commonly used vein, followed by superior thyroid vein $(\mathrm{n}=23,15.8 \%)$, external jugular vein $(n=19,13.0 \%)$, facial vein $(n=18,12.3 \%)$, and superficial temporal vein $(n=5,3.4 \%)$. With regard to arterial anastomosis method, end-to-end fashion was the most commonly used procedure ( $n=136,98.5 \%)$. In the case of veins, $80.8 \%$ of anastomoses $(n=118)$ were performed using the end-to-end method, while the others used an end-to-side method $(n=28)$ (Table 2).

\section{Outcome and complications}

The flap survival rate was $100 \%$. However, partial flap loss was noted in one patient and revised in operating room under local anesthesia (Table 3). Of 138 operations, eight (5.8\%) had to undergo exploratory surgery. The reasons for exploration were ve- 
Table 1. Patient demographics

\begin{tabular}{|c|c|}
\hline Variable & №. (\%) \\
\hline No. of patient & $127(100.0)$ \\
\hline \multicolumn{2}{|l|}{ Sex } \\
\hline Male & 107 (84.3) \\
\hline Female & $20(15.7)$ \\
\hline Smoking & $45(35.4)$ \\
\hline No. of operation & $138(100.0)$ \\
\hline \multicolumn{2}{|l|}{ Flap types } \\
\hline Radial forearm & 107 (77.5) \\
\hline Anterolateral thigh & $18(13.0)$ \\
\hline Fibular & $10(7.2)$ \\
\hline VRAM & $3(2.2)$ \\
\hline \multicolumn{2}{|l|}{ Operation type } \\
\hline First operation & $127(92.0)$ \\
\hline Reoperation & $11(8.0)$ \\
\hline \multicolumn{2}{|l|}{ Cancer type } \\
\hline SCC & $129(93.5)$ \\
\hline Ameloblastoma ${ }^{\text {a) }}$ & $3(2.2)$ \\
\hline Adenoid cystic carcinoma & $3(2.2)$ \\
\hline $\mathrm{BCC}$ & $2(1.4)$ \\
\hline Rhabdomyosarcoma & $1(0.7)$ \\
\hline \multicolumn{2}{|l|}{ Cancer site } \\
\hline Tongue & $84(60.9)$ \\
\hline Hypopharynx & $19(13.8)$ \\
\hline Larynx & $16(11.6)$ \\
\hline Tonsil & $5(3.6)$ \\
\hline Lower lip, chin, gingivab) & $9(6.5)$ \\
\hline Buccal, salivary gland, soft palate, retromolar, pyriform sinusc) & $5(3.6)$ \\
\hline \multicolumn{2}{|l|}{ Stage by TNM classification } \\
\hline NA & $3(2.2)$ \\
\hline$I+\|$ & $27(19.6)$ \\
\hline III & $33(23.9)$ \\
\hline IV & $75(54.3)$ \\
\hline \multicolumn{2}{|l|}{ Neck dissection type } \\
\hline$\|$ & $13(9.4)$ \\
\hline III & $81(58.7)$ \\
\hline IV & $13(9.4)$ \\
\hline V & $20(14.5)$ \\
\hline $\mathrm{Vl}$ & $11(8.0)$ \\
\hline
\end{tabular}

VRAM, transverse rectus abdominis myocutaneous flap; SCC, squamous cell carcinoma; BCC, basal cell carcinoma.

a)Ameloblastoma is not available staging by TNM classification; bower lip $(n=3)$, chin $(n=3)$, gingiva $(n=3)$; ${ }^{\text {clBuccal }}(n=1)$, salivary gland $(n=1)$, soft palate $(n=1)$, retromolar $(n=1)$, pyriform sinus $(n=1)$.

nous thrombosis $(\mathrm{n}=4)$, hematoma $(\mathrm{n}=3)$, and vessel kinking $(n=1)$. In all cases of venous thrombosis, the external jugular vein was used as recipient vein and was resolved with thrombectomy and re-anastomosis to the internal jugular vein.
Table 2. Recipient vessel selection and anastomosis method

\begin{tabular}{lc}
\hline Variable & No. (\%) \\
\hline Recipient artery & $138(100.0)$ \\
Total & $81(58.7)$ \\
$\quad$ Superior thyroid & $25(18.1)$ \\
Facial & $19(13.8)$ \\
Lingual & $7(5.1)$ \\
Transverse cervical & $4(2.9)$ \\
Superficial temporal & $2(1.4)$ \\
Carotid & \\
Recipient vein & $146(100.0)$ \\
Total & $75(51.3)$ \\
Internal jugular & $23(15.8)$ \\
Superior thyroid & $19(13.0)$ \\
External jugular & $18(12.3)$ \\
Facial & $5(3.4)$ \\
Superficial temporal & $3(2.1)$ \\
Transverse cervical & $3(2.1)$ \\
Lingual & $136(98.5)$ \\
Arterial anastomosis & $2(1.5)$ \\
End-to-end & \\
End-to-side & $28(19.2)$ \\
Venous anastomosis & \\
End-to-end & \\
End-to-side & \\
\hline
\end{tabular}

Table 3. Postoperative complication

\begin{tabular}{lcc}
\hline Complication & No. (\%) & Recipient vessel \\
\hline Major complication & 0 & \\
Total flap loss & $1(0.7)$ & \\
Partial flap necrosis & & \\
Minor complication & & \\
Immediate complication & $8(5.8)$ & \\
Total & $4(2.8)$ & External jugular vein (4) \\
Venous thrombosis & $3(2.2)$ & \\
Hematoma & $1(0.7)$ & \\
Vessel kinking & & \\
Long-term complication & $14(10.1)$ & \\
Total & $3(2.2)$ & \\
Fistula & $10(7.2)$ & \\
Wound dehiscence & $1(0.7)$ & \\
Infection &
\end{tabular}

With regard to long-term complications, 14 patients presented the formation of fistula $(n=3)$, partial wound dehiscence $(n=10)$ and wound infection $(n=1)$. However, the majority of complications were resolved with a simple operation under local anesthesia. Surgical site infection observed in one patient, it was resolved with 1-week intravenous antibiotics. 


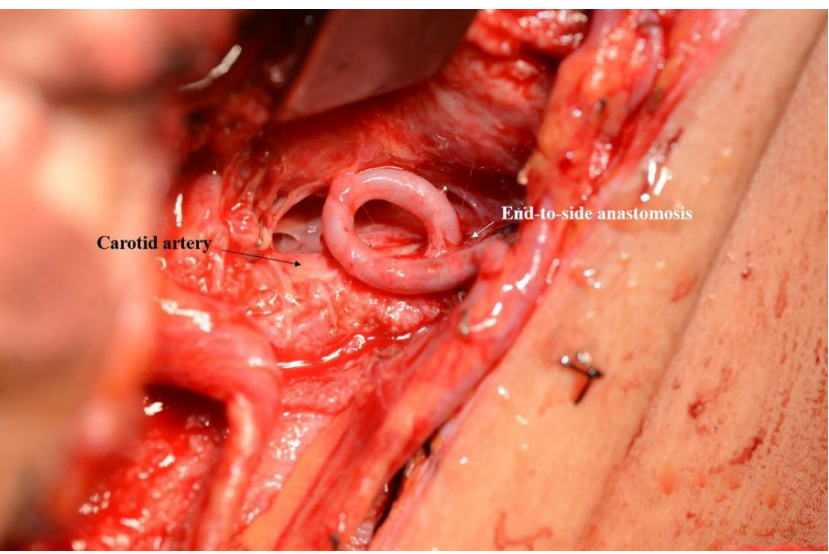

Fig. 1. Use of Carotid artery as the recipient vessel in vessel-depleted neck at second operation. Because suitable recipient arteries were sacrificed in the prior surgery, the ipsilateral carotid artery was chosen as the recipient artery. End-to-side arterial anastomosis was performed as quickly as possible.

Fig. 1 shows a case where a radial forearm free flap was used for the reconstruction of recurred tongue cancer. Because, suitable recipient arteries such as superior thyroid artery and lingual artery were sacrificed in the prior surgery, the ipsilateral carotid artery was chosen as the recipient artery. Due to high risk of vessel wall damage and limited clamping time, arterial anastomosis with end-to-side fashion was performed as quickly as possible. A branch of the internal jugular vein was chosen as the recipient vein, and the end-to-end anastomosis was performed. After reconstruction, venous congestion was observed, and exploration was planned. In intraoperative field, pedicle kinking was observed; however, the anastomosis site presented no problems. Subsequently, the pedicle was repositioned, and the flap survived without complication.

Fig. 2 shows a case with occurrence of venous thrombosis. At initial operation, hemi-glossectomy with selective neck dissection (levels I, II, III) was performed. And then, immediate reconstruction with radial forearm free flap was performed using right superior thyroid artery and right superior thyroid vein as recipient pedicles. But local recurrence was observed 3 months after initial operation, so additional resection was planned. In second operation, total glossectomy was planned, and the anterolateral thigh flap was selected as a reconstructive option. First, the lingual artery and external jugular vein were used as recipient vessels. After 24 hours has passed, however, flap congestion occurred, and immediate exploration surgery was conducted to resolve suspected vein compression. In intraoperative field, venous thrombosis was found in the external jugular vein and venous anastomosis site (Fig. 2A). Thrombectomy and massive heparin irrigation were performed, and then two endto-side anastomoses were newly performed at the side of inter-
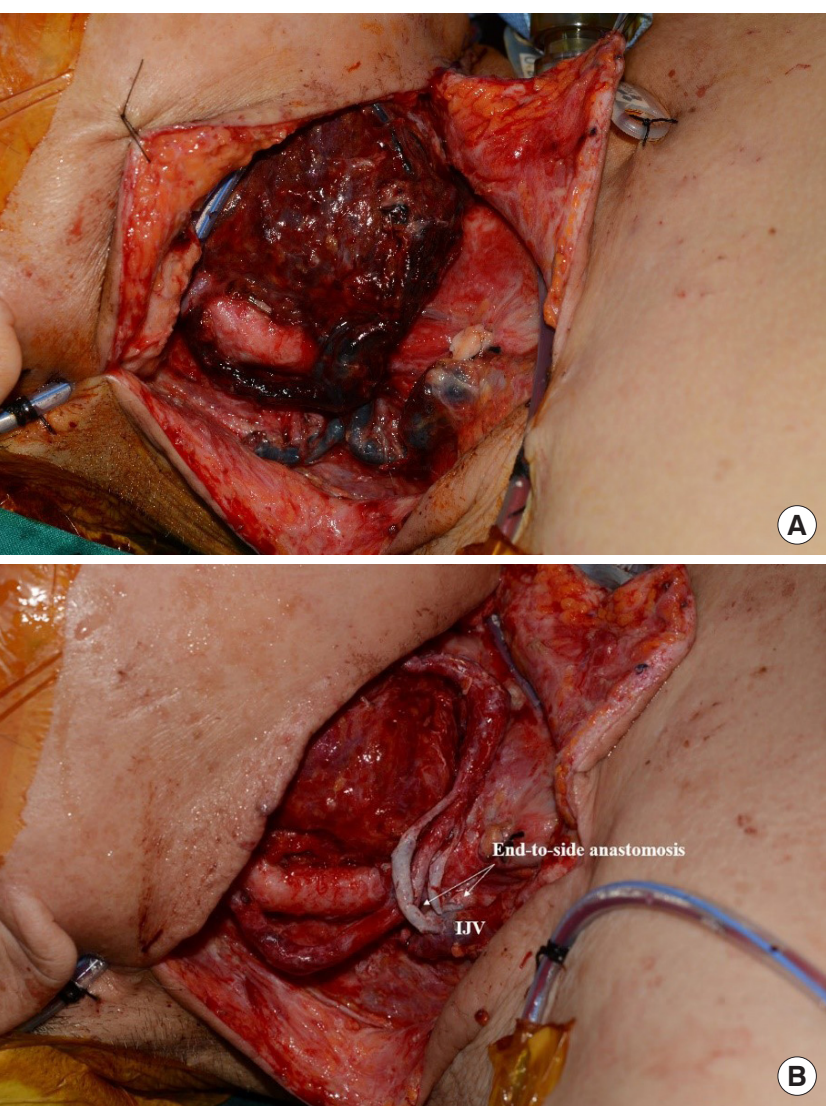

Fig. 2. Use of internal jugular vein (IJV) as an alternative recipient vessel. (A) Venous thrombosis of flap was seen in a day after reconstruction. In intraoperative view, venous thrombosis was found in external jugular vein and venous anastomosis site. (B) Thrombectomy and massive heparin irrigation were conducted, and two venous re-anastomosis was performed to IJV in an end-to-side fashion. After exploration, venous congestion resolved and flap survived without any complications.

nal jugular vein sites (Fig. 2B). After exploration, the flap survived without any postoperative complications.

\section{DISCUSSION}

Free tissue transfer in the head and neck region is considered as a challenge to reconstructive surgeons due the complexity of vascular anatomy. Although microvascular reconstruction has advanced and the success rate became higher, flap failure still has been reported in many studies. In a recent study, the rate of surgical re-exploration to evaluate microvascular anastomosis was reported to be approximately 9.7\% [10].

In the literature, successful microvascular reconstruction is dependent on three basic components of preoperative evaluation of the patient, technical aspect of the operation, and postoperative management $[11,12]$. Preoperatively, it can be associated with proper patient selection and thorough comorbidity 
assessment. Intraoperatively, preparation of donor and recipient vessels, anastomosis technique, and proper flap inset are important. Postoperatively, maintaining hemodynamic stability is the main factor [7]. Among above three basic components, proper selection of recipient vessels is one of the key factors, because it is associated with the maintenance of vascular patency.

So far, a few studies regarding selection of appropriate recipient vessel have been published. First, Liang et al. [10] reported a $90.3 \%$ flap success rate using superior thyroid artery $(77.4 \%)$ and internal jugular vein (91.4\%) as recipient vessels. Second, Yagi et al. [13] analyzed selection of appropriate recipient vessel based on neck dissection type. The authors recommended superior thyroid artery and internal jugular vein as the primary choice in type III dissection at the supraomohyoid level. In our study, type III neck dissection accounted for $58.7 \%$ of all cases $(n=81)$. Therefore, Yagi's study supports our choice of superior thyroid artery and internal jugular vein as recipient vessels.

In addition, according to Yazar's study, recipient vessel selection depends on soft tissue defect site after tumor resection. In their study, the authors recommended use of facial vessel/superior thyroid artery and internal jugular vein as recipient vessels in mid and lower third defects [14]. In particular, the authors stated the disadvantages of the external jugular vein as relatively low flow rate and small caliber, and the internal jugular vein shows higher success rate without thrombus formation. Their opinion corresponds with our results and experience. The majority of our cases composed of the mid or lower thirds defect in the head and neck region including tongue, hypopharynx, larynx, tonsil, and gingiva. In our retrospective analysis, superior thyroid artery was the most commonly used in arterial anastomosis (58.7\%), and internal jugular vein (51.3\%) was also the first choice for vein anastomosis.

In some reports, the superior thyroid artery is considered inappropriate as a recipient vessel because its diameter is only 1.5 $\mathrm{mm}[6]$. However, in our opinion, the diameter of the frequently used flap pedicle is similar to that of the superior thyroid artery. For example, the diameter of the radial artery $1 \mathrm{~cm}$ below the origin is approximately $2.3 \mathrm{~mm}$ [15], and the diameter of the lateral circumflex femoral artery is approximately 1.75-3 $\mathrm{mm}$ [16]. The peroneal artery and deep inferior epigastric artery are approximately 1-2 $\mathrm{mm}$ and $3.2 \mathrm{~mm}$ in diameter, respectively [17]. In case that the deep inferior epigastric artery was used, a diameter discrepancy was evident, however it could be overcome by using a facial vessel as the recipient vessel.

Easier vessel positioning and dissection was also the advantage of the superior thyroid artery, because it is usually dissected during the neck dissection procedure. Conversely, transverse cervical artery and carotid artery show higher risk of vessel rupture because they are more difficult to dissect and should be dissected independent of the neck dissection procedure. Furthermore, when using the carotid artery, clamping time is limited. In our first case, because no other choice was available, the carotid artery was used for the end-to-side anastomosis; however, in our opinion, the carotid artery or transverse cervical artery should be considered as the last resort because of above mentioned limitations.

With regard to recipient vein, the internal jugular vein seems to be most appropriate because this vein has a number of branches and is easy to approach. If the appropriate recipient vein is difficult to find in the defect site, the problem can be easily solved by anastomosis to the internal jugular vein with endto-side fashion. Also, in literature review, internal jugular vein has been recommended as a recipient vein for a variety of reasons. First, Swartz et al. [18] reported that anastomosis in the internal jugular vein lowers thrombus risk because its voluminous blood flow can wash away small thrombi. Second, Yamamoto et al. [19] reported that the capacity of the internal jugular vein was enough to withstand more than two end-to-side anastomoses and suggested internal jugular vein as a primary option for free flap procedures. Conversely, the external jugular vein has relatively lower flow rate and smaller caliber than the internal jugular vein. Also, it can be compressed depending on patient position. In our second case, venous congestion occurred due to compression of the external jugular vein; thus, exploration surgery was performed with re-anastomosis to internal jugular vein. In our case series, only one venous anastomosis was performed in most cases $(n=130,94.2 \%)$ and two venous anastomoses were performed in the remaining patients. $(\mathrm{n}=8,5.8 \%)$.

According to prior studies, vein graft is frequently used because it is an effective means of increasing the length of a pedicle [20-23]. However, in our case series, no vein graft was needed. There may be several interpretations. First, there were few cases of insufficient pedicle length because the pedicle was dissected to the origin as far as possible and taken at least $10 \mathrm{~cm}$. Secondly, in few cases with insufficient pedicle length, end-toside anastomosis to the adjacent main vein (e.g., internal or external jugular vein) was prioritized rather than using vein graft.

Based on these considerations, we suggest superficial thyroid artery and internal jugular vein as the first choice in head and neck reconstruction, especially in mid or lower third defects. Regarding the artery, superior thyroid artery is considered as a first choice. If the superior thyroid artery is not available, facial artery, superficial temporal artery, or lingual artery can be considered depending on defect site. If there is no other choice, transverse cervical artery and carotid artery can be considered. 
Regarding the vein, internal jugular vein is considered the first choice. Similarly, facial vein or superficial temporal vein can be considered depending on defect site. The external jugular vein or transverse cervical vein can be considered as the last choice.

There were several limitations that could influence our suggestion. First, the defect location was limited to the mid or lower third portion in this study. Therefore, in case of the upper third of the face, the choice of recipient vessel may vary depending on the vessel state and accessibility. Second, the sample size was relatively small, and selection bias could have occurred due to the retrospective study design. If additional data are obtained, more meaningful results may be achieved. Also, since the selection of recipient vessel is affected by various factors, the type of flap or the presence of radiotherapy must be separately considered. Although not analyzed in this study, further research is needed for analysis.

In conclusion, a wide range of recipient vessel options is available for head and neck reconstruction resulting from resection of head and neck cancer. Based on the retrospective analysis in this study, we suggest superficial thyroid artery and internal jugular vein as the first choice in head and neck reconstruction. With careful selection of recipient vessel, it is expected to improve the outcome and reduce the need for revision.

\section{NOTES}

\section{Conflict of interest}

No potential conflict of interest relevant to this article was reported.

\section{Ethical approval}

The study was approved by the Institutional Review Board of Korea University Anam Hospital (IRB No. 2020AN0019) and performed in accordance with the principles of the Declaration of Helsinki. Written informed consents were obtained.

\section{Patient consent}

The patients provided written informed consent for the publication and the use of their images.

\section{ORCID}

Jae-Ho Chung
Ki-Jae Kim
Kwang-Yoon Jung
Seung-Kuk Baek
Seung-Ha Park
Eul-Sik Yoon

https://orcid.org/0000-0002-8351-2444 https://orcid.org/0000-0002-0979-6688 https://orcid.org/0000-0003-4316-0779 https://orcid.org/0000-0002-4751-0337 https://orcid.org/0000-0002-2667-2791 https://orcid.org/0000-0001-5734-6625

\section{REFERENCES}

1. Ferlay J, Shin HR, Bray F, Forman D, Mathers C, Parkin DM. Estimates of worldwide burden of cancer in 2008: GLOBOCAN 2008. Int J Cancer 2010;127:2893-917.

2. Serletti JM, Higgins JP, Moran S, Orlando GS. Factors affecting outcome in free-tissue transfer in the elderly. Plast Reconstr Surg 2000;106:66-70.

3. Colen LB, Stevenson A, Sidorov V, Potparic Z, Pacelli E, Searles J, et al. Microvascular anastomotic thrombosis in experimental diabetes mellitus. Plast Reconstr Surg 1997;99:156-62.

4. Bengtson BP, Schusterman MA, Baldwin BJ, Miller MJ, Reece GP, Kroll SS, et al. Influence of prior radiotherapy on the development of postoperative complications and success of free tissue transfers in head and neck cancer reconstruction. Am J Surg 1993;166:326-30.

5. Moon KC, Lee JM, Baek SO, Jang SY, Yoon ES, Lee BI, et al. Choice of recipient vessels in muscle-sparing transverse rectus abdominis myocutaneous flap breast reconstruction: a comparative study. Arch Plast Surg 2019;46:140-6.

6. Chang EI. Pharyngeal and esophageal reconstruction. In: Neligan PC, editor. Plastic surgery. 4th ed. New York; Elsevier Inc; 2013. p. 351-2.

7. Nahabedian MY, Singh N, Deune EG, Silverman R, Tufaro AP. Recipient vessel analysis for microvascular reconstruction of the head and neck. Ann Plast Surg 2004;52:148-55.

8. Chung SW, Byun IH, Lee WJ. Sequential reconstruction for recurrent head and neck cancer: a 10-year experience. Arch Plast Surg 2019;46:449-54.

9. Ross GL, Ang ES, Golger A, Lannon D, Addison P, Snell L, et al. Which venous system to choose for anastomosis in head and neck reconstructions? Ann Plast Surg 2008;61:396-8.

10. Liang J, Yu T, Wang X, Zhao Y, Fang F, Zeng W, et al. Free tissue flaps in head and neck reconstruction: clinical application and analysis of 93 patients of a single institution. Braz J Otorhinolaryngol 2018;84:416-25.

11. Khouri RK. Avoiding free flap failure. Clin Plast Surg 1992;19: 773-81.

12. Kanoh N, Dai CF, Ikeda N, Mimura O. Parameters for the preoperative evaluation of arteriosclerosis for free-flap transfers in head and neck surgery. Clin Otolaryngol Allied Sci 2000;25: 135-8.

13. Yagi S, Suyama Y, Fukuoka K, Takeuchi H, Kitano H. Recipient vessel selection in head and neck reconstruction based on the type of neck dissection. Yonago Acta Med 2016;59:159-62.

14. Yazar S. Selection of recipient vessels in microsurgical free tissue reconstruction of head and neck defects. Microsurgery 2007;27:588-94. 
15. Shima H, Ohno K, Michi K, Egawa K, Takiguchi R. An anatomical study on the forearm vascular system. J Craniomaxillofac Surg 1996;24:293-9.

16. Chou EK, Ulusal B, Ulusal A, Wei FC, Lin CH, Tsao CK. Using the descending branch of the lateral femoral circumflex vessel as a source of two independent flaps. Plast Reconstr Surg 2006; 117:2059-63.

17. Colohan S, Maia M, Langevin CJ, Donfrancesco A, Shirvani A, Trussler AP, et al. The short- and ultrashort-pedicle deep inferior epigastric artery perforator flap in breast reconstruction. Plast Reconstr Surg 2012;129:331-40.

18. Swartz WM, Banis JC, Newton ED, Ramasastry SS, Jones NF, Acland R. The osteocutaneous scapular flap for mandibular and maxillary reconstruction. Plast Reconstr Surg 1986;77:53045.
19. Yamamoto Y, Nohira K, Kuwahara H, Sekido M, Furukawa H, Sugihara T. Superiority of end-to-side anastomosis with the internal jugular vein: the experience of 80 cases in head and neck microsurgical reconstruction. Br J Plast Surg 1999;52:88-91.

20. Zhang F, Ho PR, Chin BT, Ozek C, Buncke HJ, Lineaweaver WC. Effect of vein grafting on the survival of microvascularly transplanted muscle flaps. Microsurgery 1996;17:512-6.

21. Miller MJ, Schusterman MA, Reece GP, Kroll SS. Interposition vein grafting in head and neck reconstructive microsurgery. J Reconstr Microsurg 1993;9:245-52.

22. Germann G, Steinau HU. The clinical reliability of vein grafts in free-flap transfer. J Reconstr Microsurg 1996;12:11-7.

23. Kim HS, Chung $\mathrm{CH}$, Chang YJ. Free-flap reconstruction in recurrent head and neck cancer: a retrospective review of 124 cases. Arch Craniofac Surg 2020;21:27-34. 